\title{
PROPOSTA DE IMPLANTAÇÃO DE NÚCLEO DE SEGURANÇA DA PESSOA IDOSA INSTITUCIONALIZADA
}

Autores: Thiago S. Bezerra [1] ; Larissa A. Costa ${ }^{[1]}$; Natalia C. L. Benati ${ }^{[1]}$; Tatiana M. C. Mendes ${ }^{[1]}$; Vilani M. A.Nunes ${ }^{[2]}$

QualiSaúde ${ }^{\circledR}$

\section{INTRODUÇÃO}

Uma das formas de promover e apoiar a implantação de iniciativas voltadas à segurança do paciente é a implantação de núcleos de segurança nos estabelecimentos de saúde. Considerando o elevado número de idosos no país que se encontra residindo em Instituições de Longa Permanência (ILPI) se faz necessário um olhar diferenciado a essa faixa etária. As instituições que o abrigam geralmente não conseguem arcar sozinhas com a complexidade do cuidado devido ao acometimento de múltiplas doenças e agravos crônicos, onde necessitam ser acompanhados de forma sistemática. Nessa perspectiva, surge a proposta do PROJETO LONGEVIVER do Departamento de Saúde coletiva juntamente com o INSTITUTO ENVELHECER, ambos da UFRN para ampliar e implementar ações voltadas a melhoria do cuidado à pessoa idosa.

\section{OBJETIVO}

O presente trabalho tem como objetivo apresentar uma proposta de implantação do Núcleo de Segurança da Pessoa Idosa (NSPI) voltado à melhoria do cuidado na perspectiva de contribuir para a qualificação dos profissionais em oferecer uma assistência segura. Neste sentido, pretende-se que os profissionais que trabalham com idosos consigam proporcionar a estes um bem estar bio-psico-social em todos os níveis de atenção à saúde, potencializando suas funções globais, e, obtendo assim uma maior independência e autonomia.

\section{REFERÊNCIAS:}

1. Implantação do Núcleo de Segurança do Paciente em Serviços de Saúde - Série Segurança do Paciente e Qualidade em Serviços de Saúde/Agência Nacional de Vigilância Sanitária - Brasília: ANVISA, 2016.2.

2. Brasil. Ministério da Saúde. Secretaria de Atenção à Saúde. Departamento de Atenção Básica. Envelhecimento e saúde da pessoa idosa / Ministério da Saúde, Secretaria de Atenção à Saúde, Departamento de Atenção Básica - Brasília: Ministério da Saúde, 2006. 192 p. il. - (Série A. Normas e Manuais Técnicos) (Cadernos de Atenção Básica, n. 19).

[1] Membros Colaboradores do Projeto LONGEVIVER. [2] Prof ${ }^{a}$ Drª DSC/UFRN.Coordenadora do Projeto LONGEVIVER.
A trajetória a ser realizada constará de oficinas de preparação entre as instituições, universidade e vigilância sanitária no sentido de discutir a legislação relacionada à segurança e organização de protocolos.

\section{RESULTADOS ESPERADOS}

Os resultados esperados com a implantação do NSPI permitirá uma redução contínua dos riscos para todos os residentes em ILPI, além de capacitar os profissionais para a melhoria da qualidade dos serviços oferecidos nas instituições, como também proporcionar um ambiente seguro, que permite criar e monitorar indicadores da qualidade na instituição, padronizando processos e dessa forma, possibilitando expressar melhor a sua missão.

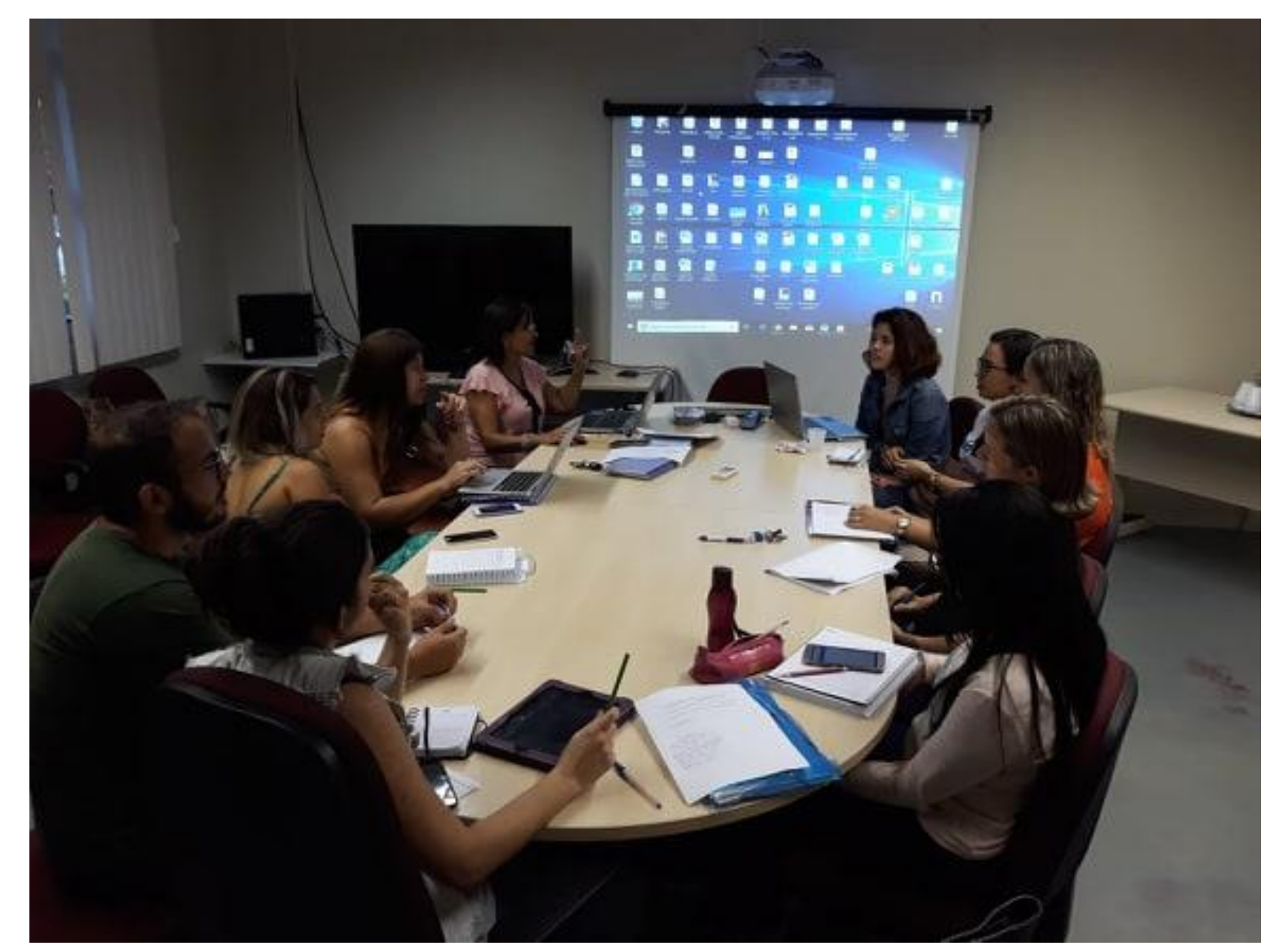

Reunião de Planejamento da criação do núcleo de segurança da pessoa idosa institucionalizada



Material de Apoio - Caderno para "Implantação do Núcleo de Segurança do Paciente". ANVISA/ 2017 